\title{
Sol-Gel Processing of Silica Nuclear Waste Glasses
}

\author{
Andrzej Deptuła ${ }^{1}$, Magdalena Milkowska ${ }^{1}$, Wiesława Lada $^{1}$, Tadeusz Olczak ${ }^{1}$, Danuta Wawszczak ${ }^{1}$, \\ Tomasz Smolinski ${ }^{1}$, Fabio Zaza ${ }^{2}$, Marcin Brykala ${ }^{1}$, Andrzej G. Chmielewski ${ }^{1}$, Kenneth C. Goretta ${ }^{3}$ \\ ${ }^{1}$ Institute of Nuclear Chemistry and Technology (INCT), Warsaw, Poland; ${ }^{2}$ Italian National Agency for New Technologies, Energy and \\ Environment (ENEA), CR Casaccia, Rome, Italy; ${ }^{3}$ Asian Office of Aerospace Research and Development, Japan. \\ Email: a.deptula@ichtj.waw.pl
}

Received June 30 $0^{\text {th }}$, 2011; revised August 9 $9^{\text {th }}$ 2011; accepted August 21 $1^{\text {th }}, 2011$.

\begin{abstract}
A complex Sol-Gel process has been used for synthesis of silica glasses designed to contain high-level nuclear wastes. $\mathrm{Cs}, \mathrm{Sr}, \mathrm{Co}$, and Nd (generically denoted Me) were used, the last as surrogate for actinides. Gels in the form of powders and sintered compacts were prepared by hydrolysis and polycondensation of tetraethoxide/Me nitrate solutions, which contained ascorbic acid as a catalyst. Thermal treatment studies were conducted on the resulting gels. Transformation to final products was studied by thermogravimetric analysis, infrared spectroscopy, and X-ray diffraction. Preliminary testing of Me leaching was also completed in quiescent water. Only a single dense form was resistant to leaching.
\end{abstract}

Keywords: Sol-Gel, Silica Glass, Nuclear Waste, Thermal Treatment

\section{Introduction}

Vitrification of hazardous nuclear wastes has been shown to be a viable technological alternative for effecttive management of spent fuel and radioactive waste. The advantages of the method are that a large number of elements that can be incorporated into the glass and a highly durable and small-volume waste is produced [1,2]. The properties of silica glasses, including good durability and mechanical strength and ability to incorporated large concentrations of metallic dopants, make them ideal candidates for matrices for nuclear waste storage $[3,4]$. The most significant disadvantage of silica glasses for such use is their high processing temperature of $\sim 2000^{\circ} \mathrm{C}$. Sintering of sol-gel-derived glasses can be accomplished at much lower temperatures, and sol-gel techniques have been successfully used for preparation of porous glass hosts for nuclear wastes $[3,4]$. Appropriately prepared, sintered ceramic bodies can have higher stabilities and be more resistant to leaching than are many melt-processed glasses $[5,6]$.

In the present work, our proprietary complex sol-gel process (CSGP) [7-9] has been adapted to synthesize silica glasses capable of incorporating significant concentrations of high-level nuclear wastes. The heavy metals (denoted $\mathrm{Me}$ ) $\mathrm{Cs}, \mathrm{Sr}, \mathrm{Co}$, and, as a surrogate for actinides, $\mathrm{Nd}$, were incorporated into silica glasses and the resulting waste forms were characterized and tested for leaching response.

\section{Experimental Details}

A detailed flow-chart for the preparation Cs-, Sr-, Co-, and Nd-doped (10 mole\%) silica gels is shown in Figure 1. Gels in the form of powders or monoliths were prepared by hydrolysis and subsequent polycondensation of tetraethoxide/Me nitrate solutions containing ascorbic acid (ASC) as a catalyst, instead of the $\mathrm{HCl}$ or $\mathrm{NH}_{4} \mathrm{OH}$ that are routinely used for catalysis in glass synthesis. ASC has not, to the best of our knowledge, been used previously in this type of processing of a nuclear waste glass. Its use has been shown to decrease remarkably the time needed to synthesize gels $[7,9]$.

Thermogravimetric analysis (TG) and differential thermal analysis (DTA) were conducted in air with a Hungarian MOM (Budapest, Hungary) $[8,9]$. The heating rate was $10^{\circ} \mathrm{C} / \mathrm{h}$.

All resulting products were analyzed by X-ray diffracttion (XRD) with a Rigaku Miniflex diffractometer (Tokyo, Japan). $\mathrm{Cu}-\mathrm{K} \alpha$ radiation was used. The tube output voltage was $30 \mathrm{kV}$ the tube output current was $15 \mathrm{~mA}$, the angular spread was $2 \theta=3^{\circ}-90^{\circ}$, with steps of $0.02^{\circ}$ and a scanning rate of $2 \% \mathrm{~min}$. Raw data were smoothed by the Savitzky method, background was eliminated by the Sonnevelt method, and $\mathrm{K} \alpha 2$ was eliminated. Infrared measurements were conducted with a Perkin Elmer Model 983 Spectrometer (Waltham, MA). The potassium bromide pellet technique was adopted.

Leaching tests were conducted on $2 \mathrm{~g}$ of material. Powder 


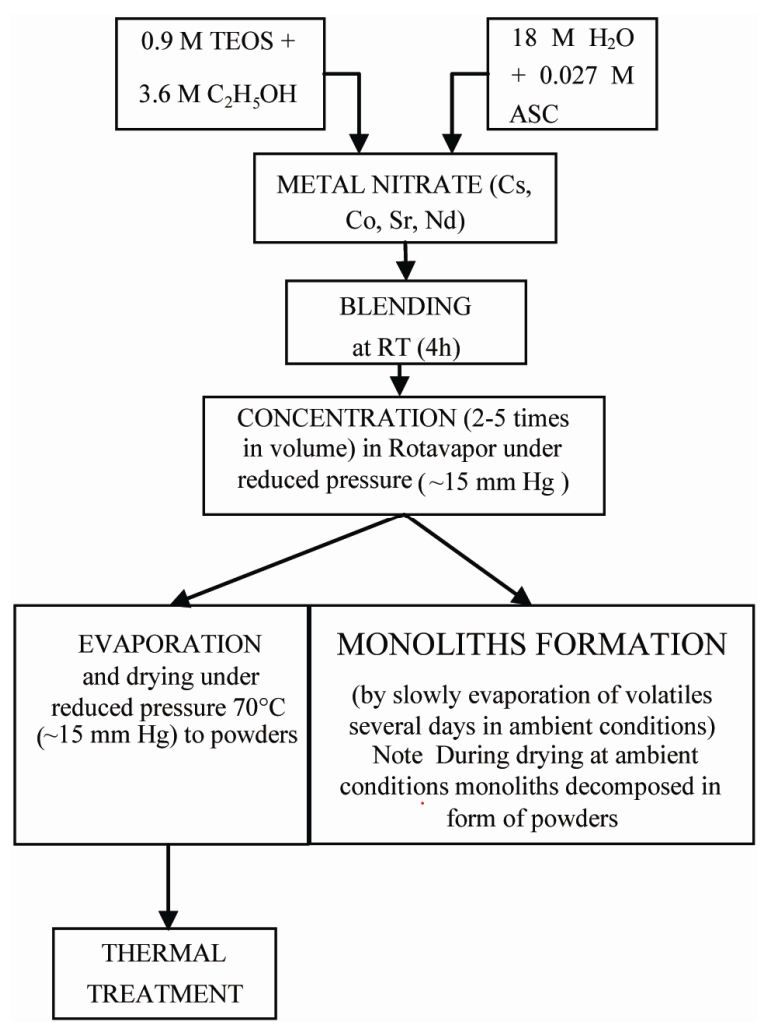

Figure 1. Flow-chart of CSGP for preparation Cs-, Sr-, Co-, and Nd-doped silica gels.

agglomerates, in some cases with alumina entrained, were placed in G4 crucibles, which were placed in $100 \mathrm{ml}$ of gently stirred deionized water at $23^{\circ} \mathrm{C}$. After each crucible was withdrawn, the water was filtered off. The Csdoped drops of glass, which attacked the platinum dish in which they were heated, were handled similarly. After drying for $2 \mathrm{~h}$ at $110^{\circ} \mathrm{C}$, the specimens were weighed. These procedures were repeated a total of 19 times. The maximum emersion time was $430 \mathrm{~h}$. Solutions were analyzed for Me and Si contents by ion chromatography [10] with a Dionex 2000/sp ion chromatograph (Sunnyvale, CA, USA) and with a Thermo Electron Corporation flame atomic absorption spectrometer, Model SOLAAR MK2 (Marietta, $\mathrm{OH}, \mathrm{USA}$ ).

There is a wide range of possibilities for leaching tests. Various specimen sizes and forms, solutions, fluid flows, and temperatures can be used [11-15]. We selected leaching of comparatively small samples of high surface area in room-temperature deionized water as a reasonable method to assess whether this type of silica-based, sol-gel-derived glass may be a viable candidate as a nuclear waste form.

\section{Results and Discussion}

The thermal decomposition of gels (dried under vacuum at $70^{\circ} \mathrm{C}$ in Rotavapor) versus temperature, $\mathrm{T}$, is illus

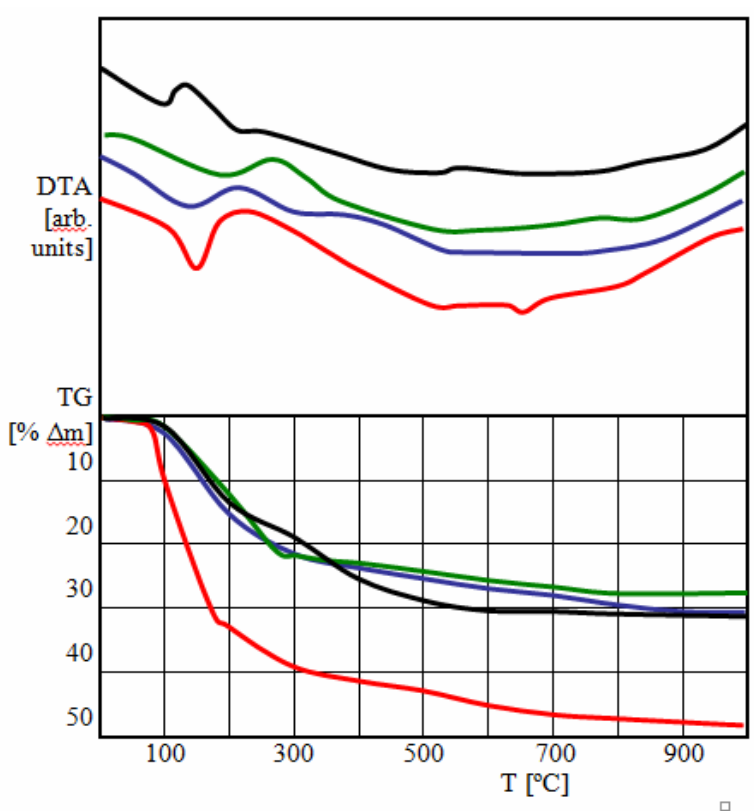

Figure 2. Thermal analysis of gel powders dried at $70^{\circ} \mathrm{C}$ : CsSi (nu); SrSi (nu); CoSi (nu); NdSi (nu).

trated in Figure 2. Various minor endotherms and exotherms were observed, but no significant phase transformation appeared to take place. For all four gels, loss of mass, $\mathrm{m}$, became significant above approximately $70^{\circ} \mathrm{C}$. The continuous mass losses are presumed to be connected with the detachment of water and $\mathrm{OH}$ groups. The mass losses became smaller above $350^{\circ} \mathrm{C}$, while the thermal decomposition was virtually complete by approximately $800^{\circ} \mathrm{C}$. By $1000^{\circ} \mathrm{C}$, the Cs-, Co-, and Nd-containing specimens lost $27-31 \%$ of their masses. The Sr-containing specimen lost $48 \%$ of its mass. The evidence from the thermal analyses conducted to $1000^{\circ} \mathrm{C}$ suggests formation of glasses for all of the heated gels.

Photographs of all materials calcined at various temperatures are shown in Figure 3. Each of the well-formed monoliths produced friable powders when heated to $70^{\circ} \mathrm{C}$. Heating to $1200^{\circ} \mathrm{C}$ produced little sintering and some color changes. Heating to $1700^{\circ} \mathrm{C}$ produced reactions with the crucibles, but only limited extents of sintering, except, in the case of Cs-containing glass, for which full melting occurred. These results are consistent with literature data [16], in which it is reported that amorphous silica powders sinter significantly by $\approx 1730^{\circ} \mathrm{C}$ and the technological melting temperature is given as $1800^{\circ} \mathrm{C}-2000^{\circ} \mathrm{C}$ [4].

Alteration of thermal treatment coupled with a coldpressing step could perhaps produce denser monolithic forms [17]. It is also possible that some sort of hot-pressing step will be required to form dense monoliths from the gels $[3,4,18]$.

Infrared spectra and XRD patterns of gels and doped silicate glasses are shown in Figure 4. The infrared spectra 

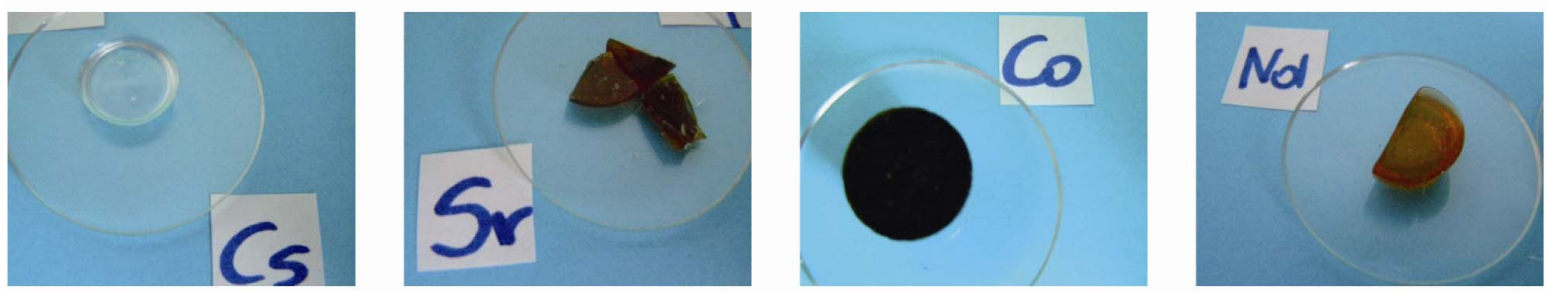

monoliths, RT
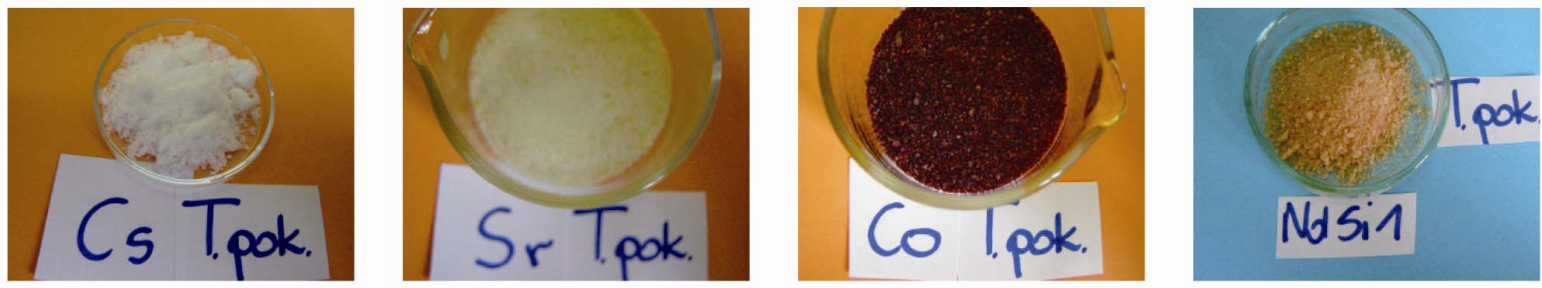

Powders, $70^{\circ} \mathrm{C}$
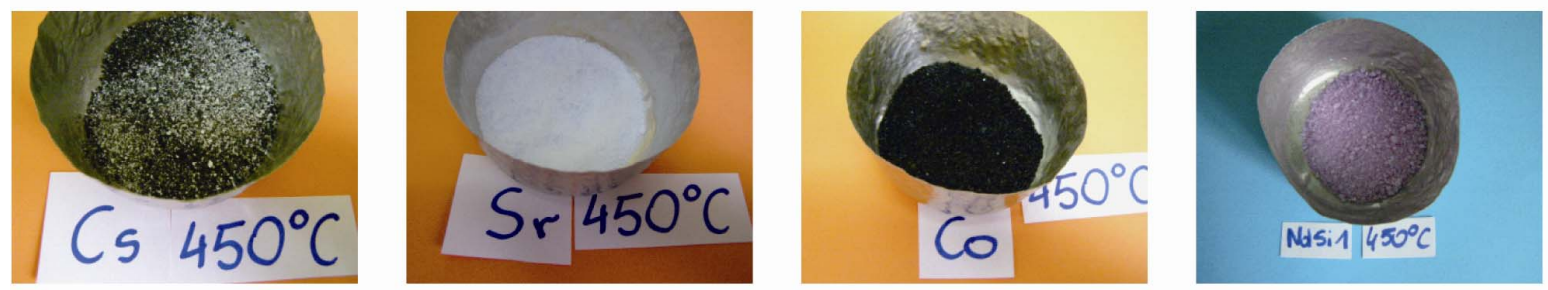

$450^{\circ} \mathrm{C}$
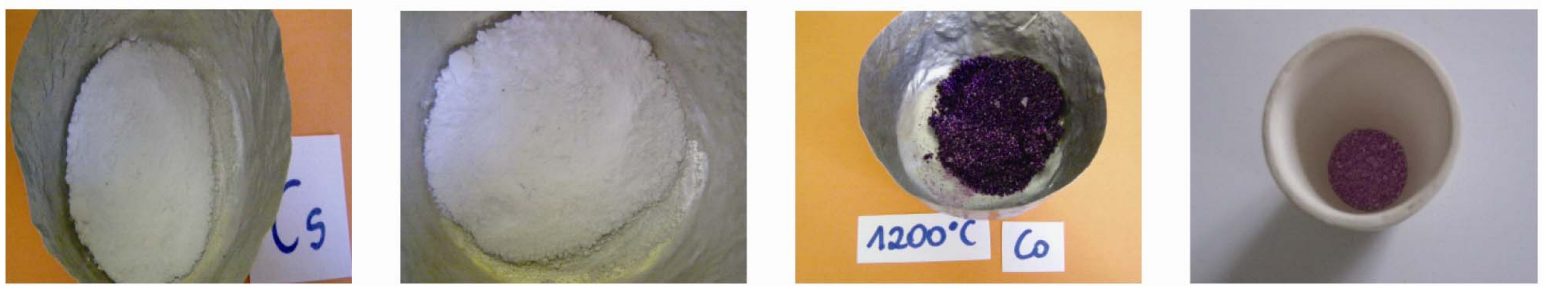

$1200^{\circ} \mathrm{C}$
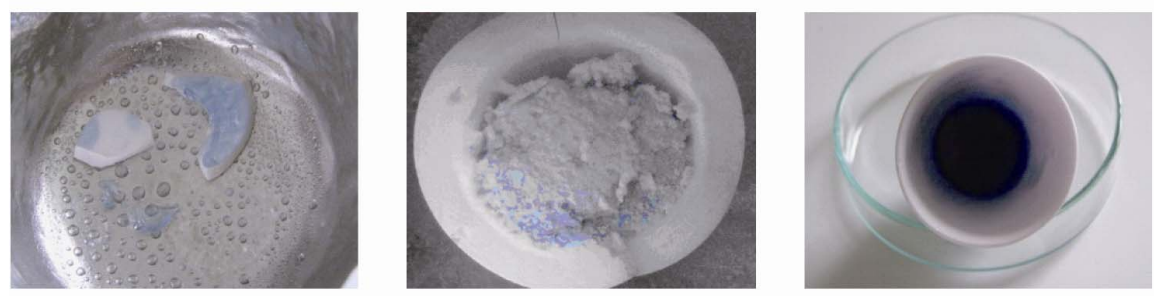

$1700^{\circ} \mathrm{C}$

Figure 3. Photographs of materials obtained from sols according procedure described in Figure 1, heated for $2 \mathrm{~h}$ at temperatures shown. 
2.5

Cs-Si

2

1.5

1

0.5

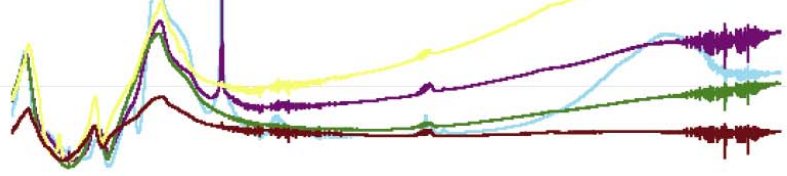

0
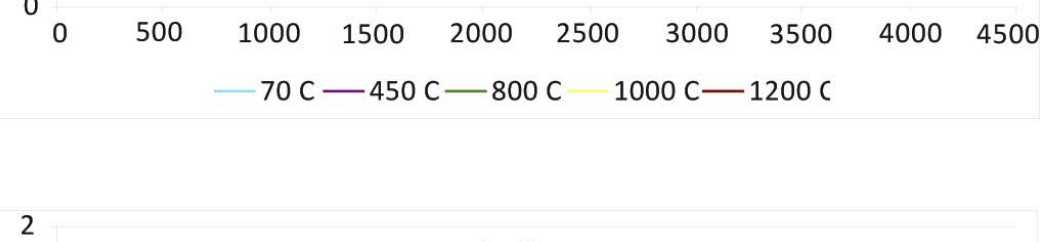

Co-Si

1.8

1.6

1.4

1.2

1

0.8

0.6

0.4

0.2

0

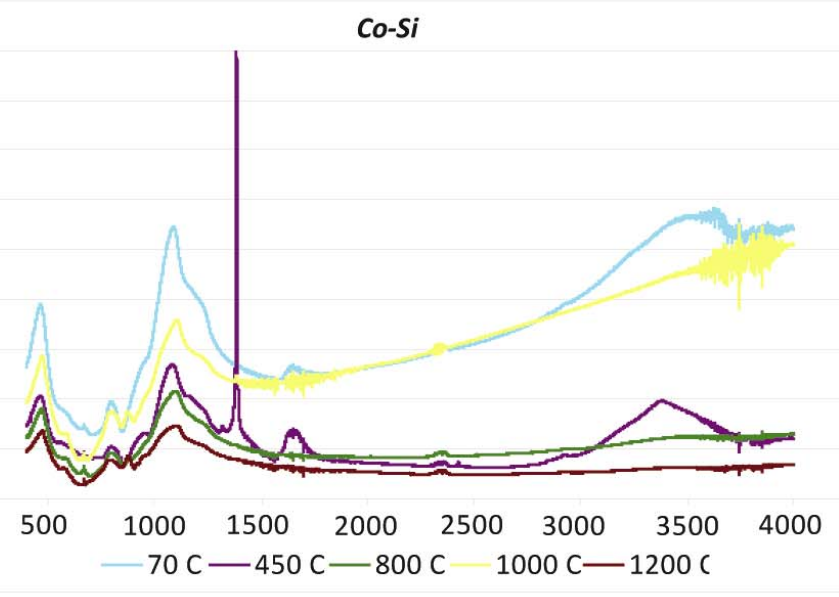

3

2.5

2

1.5

1

0.5

0

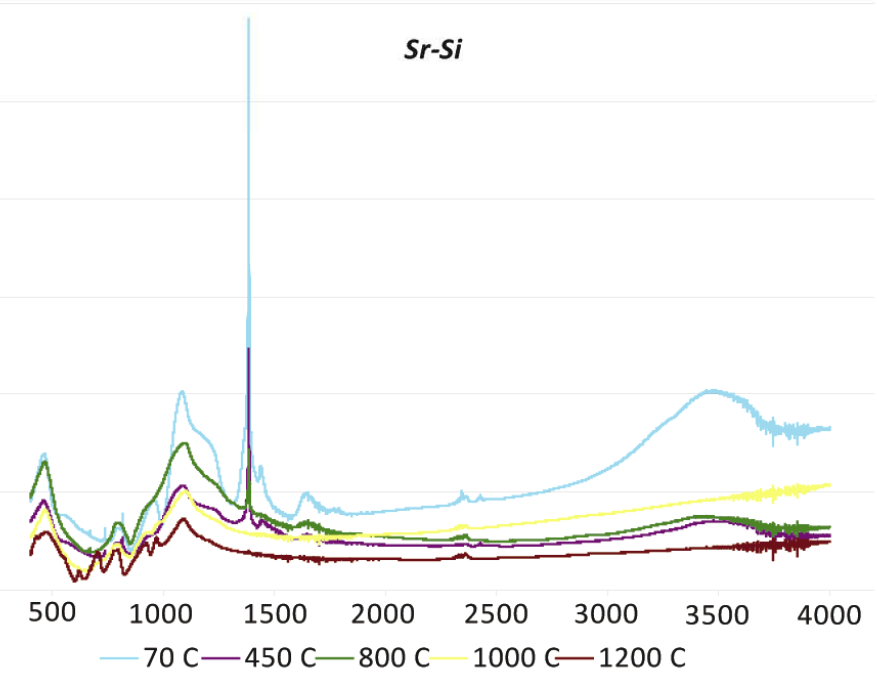

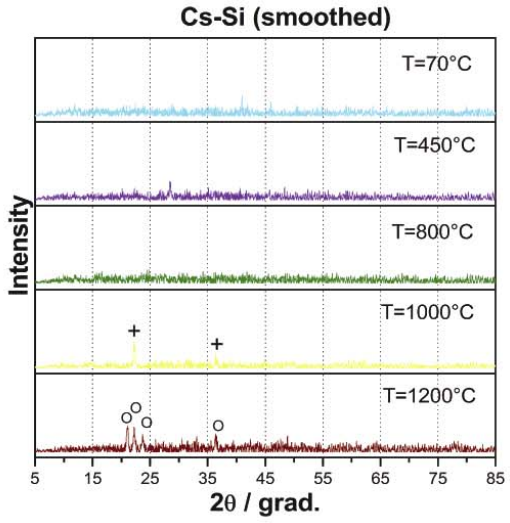

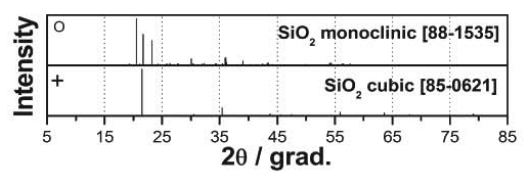

Co-Si (smoothed)

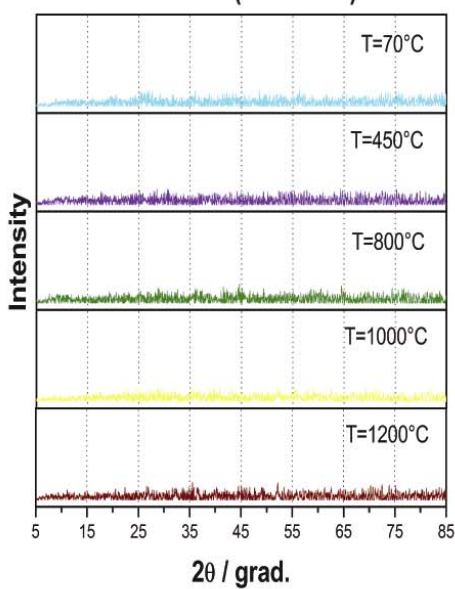

Sr-Si (smoothed)

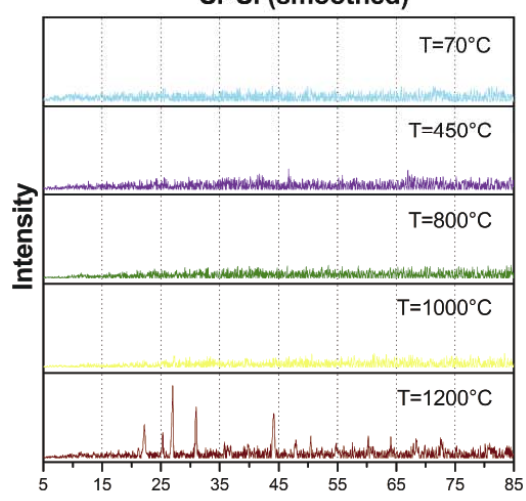

$2 \theta /$ grad.

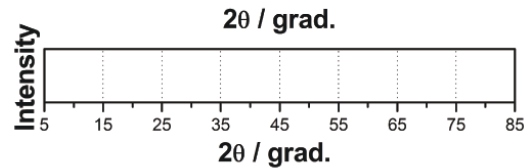



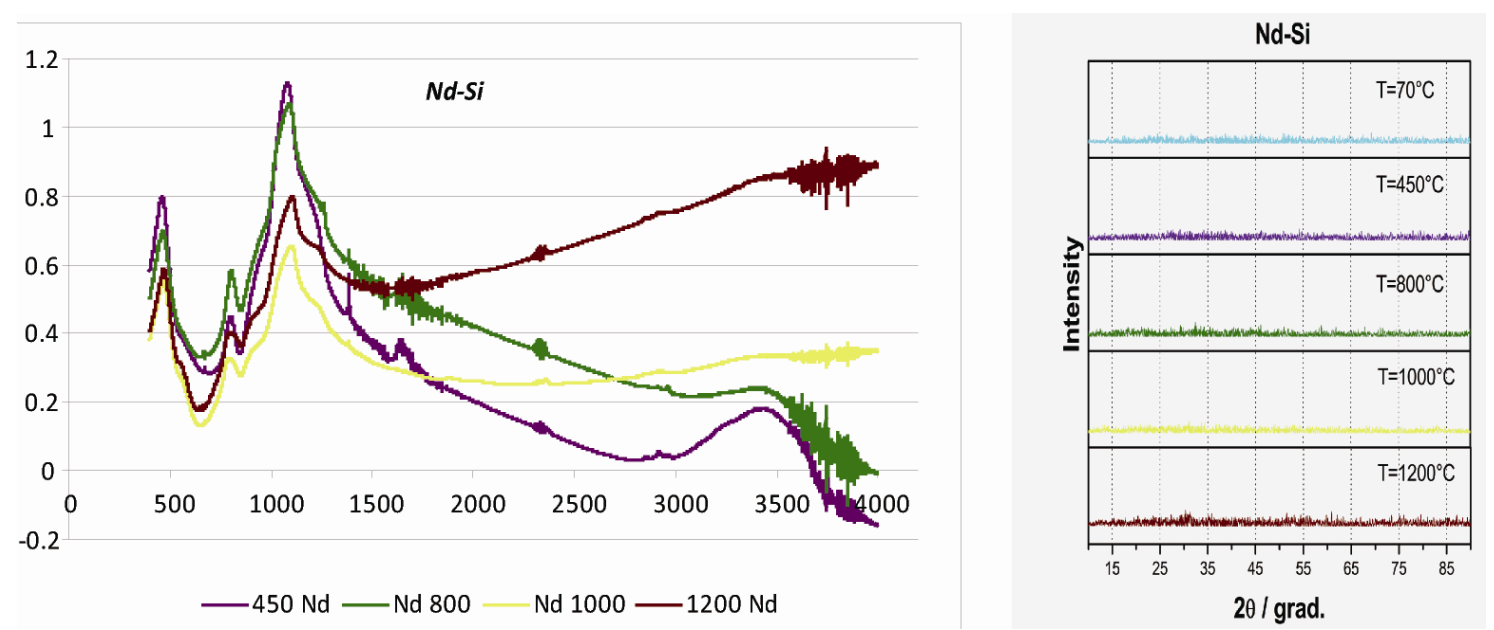

Figure 4. Infrared spectra and XRD patterns of gels and doped silicate glasses.

revealed that organic impurities did not exist in detectable concentrations at $70^{\circ} \mathrm{C} . \mathrm{H}_{2} \mathrm{O}$ and $\mathrm{OH}$ groups were identified, but these groups were not observed at higher temperatures (except for $\mathrm{Co}$ and $\mathrm{Nd}$ dopants at $450^{\circ} \mathrm{C}$ ). Significant crystallization was observed in the Cs- and Sr-doped specimens that were heated to $1200^{\circ} \mathrm{C}$.

It is interesting to note that bidentate $\mathrm{NO}_{3}^{-}$ions were observed only with the Sr- and Nd-doped silicate gels dried at $70^{\circ} \mathrm{C}$, whereas with the Cs- and Sr-doped gels, only free, non-coordinated nitrate ions were observed instead $\left(v 3 \mathrm{NO}_{3}\right.$ at $1384 \mathrm{~cm}^{-1}$, v. strong and $v 1+v 3 \mathrm{NO}_{3}^{-}$ at $2360 \mathrm{~cm}^{-1}$, v. weak), which is in accord with the observations of Bogard et al. [19]. Free nitrate ions were observed with all samples heated at $450^{\circ} \mathrm{C}$ and their traces appeared even at $800^{\circ} \mathrm{C}$ with $\mathrm{Sr}$ or $\mathrm{Nd}$ dopants present. It is difficult to explain the occurrence of a strong bonding mode of nitrates in the examined systems, because nitrates typically decompose at lower temperatures: e.g., $\mathrm{Sr}\left(\mathrm{NO}_{3}\right)_{2}$ at $\approx 640^{\circ} \mathrm{C} ; \mathrm{CsNO}_{3}$ at $\approx 400^{\circ} \mathrm{C} ; \mathrm{Co}\left(\mathrm{NO}_{3}\right)_{2}$ at $\approx 290^{\circ} \mathrm{C}$ [16]. A possible explanation may come from the fact that all of the oxygen atoms of the $\mathrm{NO}_{3}$ groups were engaged in coordination sites. In all of the spectra, typical $\mathrm{SiO}_{2}$ vibrations bands $\left(4000 \mathrm{~cm}^{-1}\right.$ and $\left.2510 \mathrm{~cm}^{-1}\right)$ were observed: Si-O-Si symmetric bending at $455-470$ $\mathrm{cm}^{-1}$, Si-O-Si symmetric stretching at $783-815 \mathrm{~cm}^{-1}$, and asymmetric stretching at $1074-1080 \mathrm{~cm}^{-1}$.

Leaching tests consisted of weight-change measurements and analysis of leachates. Use of stirred roomtemperature, deionized water will produce more rapid leaching than will, for example static, ground water tests [20], but will not allow for extrapolation to actual repository conditions and long duration [21-24]. It should allow for assessment of the applicability of the sol-gel glasses produced in this study as nuclear waste forms. Data from the studies are shown in Figure 5 and Table 1. The most obvious trends in the data in Figure 5 are that only the substantially melted, dense form (the Cs-doped, clear glass drops) exhibited a low leaching rate of the dopant and the Nd-doped, sintered, but still-porous specimen, was more resistant to leaching than were the other sintered compacts. The porous Cs- and Sr-doped specimens exhibited comparatively high leaching rates. Analyses of the metal concentrations in the leachates revealed similar trends, for both $\mathrm{Me}$ and Si concentrations. The large differences in mass loss between many of the individual weight-change tests may have been caused by changes in the corrosion mechanism. In general, glass corrosion in aqueous solutions is governed by diffusion-controlled ion exchange and dissolution of the glass network itself. Saturation of the solution can affect the processes [25]. Precipitation of surface species can also affect corrosion rates [1]. Detailed studies of the corrosion processes and surface alteration $[11,26]$ are beyond the scope of this synthesis-based work.

The leaching data are difficult to compare directly with those of other studies, owing to variations of specimen form and test conditions, but data from similar tests $[20,27]$ indicate generally higher rates for the waste forms produced in this study. The Cs-doped glass drops and the $\mathrm{Nd}$-doped (actinides surrogate) lightly sintered forms were reasonably resistant to leaching, within the analytical errors. The other forms, all porous, were clearly susceptible to leaching. In forms for which the dopants were more strongly bonded, the structure of silica matrix was also more resistant leaching (Table 1).

These studies yielded mixed results. Uniform products containing high concentrations of dopants were produced, but the products remained porous after prolonged sintering at elevated temperatures. Such porous products are not suitable for use as nuclear waste forms. Future efforts will seek to fabricate denser forms. It is possible that cold-pressing [1-5] or a tailored reaction-sintering step [6] 


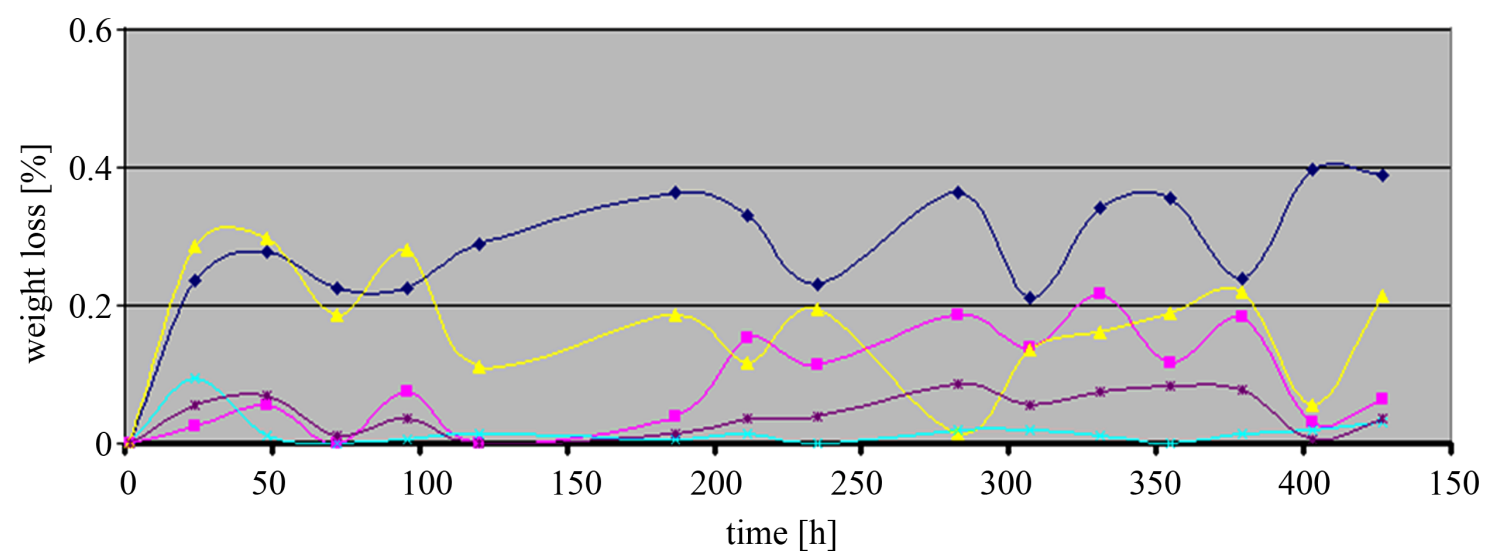

Figure 5. Leaching experiments of specimens sintered at $1700^{\circ} \mathrm{C}$, except for $\mathrm{Nd}$-doped specimen, which was sintered at $1200^{\circ} \mathrm{C}$ : Cs (includes agglomerates from alumina support (Figure 3), $\neq$ Cs (transparent glass drops (Figure 3), $\downarrow$ Sr, $\star-$ Co and - Nd.

Table 1. Analysis of leached components in at.\%; Me determined by ion chromatography and $\mathrm{Si}$ by flame atomic absorption spectrometry.

\begin{tabular}{|c|c|c|c|}
\hline $\begin{array}{c}\text { Number of } \\
\text { leachings }\end{array}$ & Me oxide & at.\% Me & at.\% of $\mathrm{SiO}_{2}$ \\
\hline 1 & Cs agregates & 0.10 & 0.18 \\
\hline 4 & “ & 0.06 & 0.22 \\
\hline 9 & “ & 0.02 & 0.00 \\
\hline 1 & Cs drops of glass & 0.001 & 0.09 \\
\hline 4 & “ & 0.00003 & 0.005 \\
\hline 9 & “ & 0.00003 & 0.02 \\
\hline 1 & Sr & 0.021 & 0.21 \\
\hline 4 & “ & 0.026 & 0.20 \\
\hline 9 & “ & 0.018 & 0.35 \\
\hline 1 & Co & 0.001 & 0.054 \\
\hline 4 & “ & 0.006 & 0.03 \\
\hline 9 & Nd & 0.0002 & 0.085 \\
\hline 1 & “ & 0.00002 & 0.025 \\
\hline 4 & 0.00002 & 0.186 \\
\hline 9 & & & \\
\hline
\end{tabular}

could result in denser final products. It is perhaps more likely that some type of hot-pressing step $[3,4,18]$ will be required.

\section{Conclusions}

Silicate glass typically containing high-level nuclear waste elements $\mathrm{Cs}, \mathrm{Sr}, \mathrm{Co}$, and $\mathrm{Nd}$ (as actinides surrogate) were synthesized directly by a complex sol-gel process, by including the dopants in starting in the starting sols. Application of ascorbic acid as a catalyst, instead of the more-common $\mathrm{HCl}$ or $\mathrm{NH}_{4} \mathrm{OH}$ that are generally used, and elevated temperature allowed for processing within several hours. XRD patterns indicated that all studied elements were, for all temperatures of heat treatment, integrally bonded in the silicate glass structures. Infrared spectra indicated that in general organic impurities did not exist after drying in vacuum at $70^{\circ} \mathrm{C} . \mathrm{H}_{2} \mathrm{O}$ and $\mathrm{OH}$ groups existed at this temperature, but they were not observed at $450^{\circ} \mathrm{C}$, except when $\mathrm{Co}$ and $\mathrm{Nd}$ dopants were present. Leaching test revealed that stabilities of powders and agglomerates sintered at $1700^{\circ} \mathrm{C}$ were not sufficient. The melted Cs-doped glass was substantially more resistant to leaching. Results indicate need to focus on densification of the final forms, either by adding pressing steps or significantly altering the sintering protocols.

\section{Acknowledgements}

This work is an initial part of studies that will be continued within Polish Governmental Project "Technology Supporting Development of Safe Nuclear Power," Part "Development of Techniques and Technologies Supporting Management of Spent Nuclear Fuel and Radioactive Waste." The authors thankful to INCT team: Dr. L. Fuks for performing IR spectra, Dr. W. Skwara for flame spectrometry analysis and Dr. K. Kulisa for ionic chromatography analysis.

\section{REFERENCES}

[1] M. I. Ojovan and W. E. Lee, "An Introduction to Nuclear Waste Immobilization,” Elsevier, London, 2005.

[2] M. I. Ojovan, J. M. Juoi and W. E. Lee, "Application of Glass Composite Materials for Nuclear Waste Immobilisation," Journal of The Pakistan Materials Society, Vol. 2, No. 2, 2008, pp. 72-76.

[3] T. Woignier, J. Reynes, J. Phalippou and J. L. Dussossoy, "Nuclear Waste Storage in Gel-Derived Materials," Journal of Sol-Gel Science and Technology, Vol. 19, 2000, pp. 833-837. 
[4] T. Woignier, J. Reynes, J. Phalippou and J. L. Dussossoy, "Sintered Silica Aerogel: A Host Matrix for Long Life Nuclear Wastes," Journal of Non-Crystalline Solids, Vol. 225, 1998, pp. 353-357. doi:10.1016/S0022-3093(98)00052-0

[5] D. R. Clarke, "Ceramic Materials for the Immobilization of Nuclear Waste," Annual Review of Materials Science, Vol. 13, 1983, pp. 191-218. doi:10.1146/annurev.ms.13.080183.001203

[6] W. L. Gong, W. Lutze and R. C. Ewing, "Reaction sintered glass: A Durable Matrix for Spinel-Forming Nuclear Waste Compositions," Journal of Nuclear Materials, Vol. 278, No. 1, 2000, pp. 73-84. doi:10.1016/S0022-3115(99)00226-3

[7] A. Deptula, W. Lada, T. Olczak, M. T. Lanagan, S. E. Dorris, K. C. Goretta and R. B. Poeppel, "Method for Preparing High-Temperature Superconductors," Polish Patent 172618, 1997.

[8] A. Deptula, J. Chwastowska, W. Lada, T. Olczak, D. Wawszczak, E. Sterlinska, B. Sartowska and K. C. Goretta, "Sol-Gel-Derived Hydroxyapatite and Its Application to Sorption of Heavy Metals," Advances in Science and Technology, Vol. 45, 2006, pp. 2198-2203. doi:10.4028/www.scientific.net/AST.45.2198

[9] A. Deptula, W. Lada, T. Olczak, D. Wawszczak, M. Brykala, F. Zaza and K. C. Goretta, "Novel Sol-Gel Synthesis of $\mathrm{LiMn}_{2} \mathrm{O}_{4}$ and $\mathrm{LiNi}_{\mathrm{x}} \mathrm{Co}_{1-\mathrm{x}} \mathrm{O}_{2}$ Powders," Advances in Science and Technology, Vol. 63, 2010, pp. 14-23. doi:10.4028/www.scientific.net/AST.63.14

[10] P. R. Haddad, "Comparison of Ion Chromatography and Capillary Electrophoresis for the Determination of Inorganic Ions," Journal of Chromatography A, Vol. 770, No. $1-2,1997$, pp. 281-290. doi:10.1016/S0021-9673(96)01085-0

[11] J. A. Stone, "An Overview of Factors Affecting the Leachability of Nuclear Waste Forms," Nuclear and Chemical Waste Management, Vol. 2, No. 2, 1981, pp. 113-118. doi:10.1016/0191-815X(81)90026-7

[12] A. Barkatt, E. E. Saad, R. Adiga, W. Sousanpour, Al. Barkatt, M. A. Adel-Hadadi, J. A. O'Keefe and S. Alterescu, "Leaching of Natural and Nuclear Waste Glasses in Sea Water," Applied Geochemistry, Vol. 4, No. 6, 1989, pp. 593-603. doi:10.1016/0883-2927(89)90069-3

[13] W. L. Ebert, "Effects of the Glass Surface Area/Solution Volume Ratio on Glass Corrosion: A Critical Review," ANL-94/34, Argonne National Laboratory, 1994.

[14] J. R. Martinez, E. Espericueta and G. Ortega-Zarzosa, "Effect of Aging of Chlorophyll Species Embeded in Silica Xerogels Matrix," New Journal of Glass and Ceramics, Vol. 1, No. 1, 2011, pp. 7-12.

[15] L. Werme, I. K. Björner, G. Bart, H. U. Zwicky, B. Grambow, W. Lutze, R. C. Ewing and C. Magrabi, "Chemical corrosion of highly radioactive borosilicate nuclear waste glass under simulated repository conditions," Journal of Materials Research, Vol. 5, No. 5, 1990, pp. 1130-1146. doi:10.1557/JMR.1990.1130

[16] E. M. Rabinovich, "Preparation of Glass by Sintering," Journal of Materials Science, Vol. 20, No. 12, 1985, pp.
4259-4297. doi:10.1007/BF00559317

[17] J. Phalippou, M. Prassas and J. Zarzycki, "Crystallization of Gels and Glasses Made from Hot-Pressed Gels," Journal of Non-Crystalline Solids, Vol. 48, No. 1, 1982, pp. 17-30. doi:10.1016/0022-3093(82)90243-5

[18] M. Nishioka, S. Hirai, K. Yanagisawa and N. Yamasaki, "Solidification of Glass Powder with Simulated HighLevel Radioactive Waste During Hydrothermal Hot-Pressing”, Journal of the American Ceramic Society, Vol. 73, No. 2, 1990, pp. 317-322. doi:10.1111/j.1151-2916.1990.tb06512.x

[19] J. S. Bogard, S. A. Johnson, R. Kumar and P. T. Cunningham, "Quantitative Analysis of Nitrate Ion in Ambient Aerosols by Fourier-Transform Infrared Spectroscopy," Environmental Science and Technology, Vol. 16, No. 3, 1982, pp. 136-140. doi:10.1021/es00097a004

[20] A. N. Sharaf El-Deen, M. M. El-Dessouky, M. A. Helmy, M. Wagdy, A. Raouf and M. I. El-Dessouky, "Characterization and Leach Investigation of Sodium Silicate Matrices Used for Immobilization of Radioactive Waste,' in M. F. Barakat, Ed., Proceedings of Second Arab Conference on the Peaceful Uses of Atomic Energy, Cairo, 5-9 November 1994, pp. 375-391.

[21] G. Malow, W. Lutze and R. C. Ewing, "Alteration Effects and Leach Rates of Basaltic Glasses: Implications for the Long-Term Stability of Nuclear Waste Form Borosilicate Glasses," Journal of Non-Crystalline Solids, Vol. 67, 1984, pp. 305-321. doi:10.1016/0022-3093(84)90156-X

[22] L. Werme, I. K. Björner, G. Bart, H. U. Zwicky, B. Grambow, W. Lutze, R. C. Ewing and C. Magrabi, "Chemical Corrosion of Highly Radioactive Borosilicate Nuclear Waste Glass Under Simulated Repository Conditions," Journal of Materials Research, Vol. 5, No. 5, 1990, pp. 1130-1146. doi:10.1557/JMR.1990.1130

[23] G. Leturcq, G. Berger, T. Advocat and E. Vernaz, "Initial and Long-Term Dissolution Rates of Aluminosilicate Glasses Enriched with Ti, Zr and Nd," Chemical Geology, Vol. 160, 1999, pp. 39-62. doi:10.1016/S0009-2541(99)00055-8

[24] J. Sterpenich and G. Libourel, "Using Stained Glass Windows to Understand the Durability of Toxic Waste Matrices," Chemical Geology, Vol. 174, 2001, pp. 181-193. doi:10.1016/S0009-2541(00)00315-6

[25] M. I. Ojovan, R. J. Hand, N. V. Ojovan and W. E. Lee, "Corrosion of Alkali-Borosilicate Waste Glass K-26 in Non-Saturated Conditions," Journal of Nuclear Materials, Vol. 340, 2005, pp. 12-24. doi:10.1016/j.jnucmat.2004.10.095

[26] W. L. Gong, L. M. Wang, R. C. Ewing, E. Vernaz, J. K. Bates and W. L. Ebert, "Analytical Electron Microscopy Study of Surface Layers Formed on the French SON68 Nuclear Waste Glass during Vapor Hydration at $200^{\circ} \mathrm{C}$," Journal of Nuclear Materials, Vol. 254, 1998, pp. 249-265. doi:10.1016/S0022-3115(97)00349-8

[27] P. R. Aravind, L. Sithara, P. Mukundan, P. Krishna Pillai and K. G. K. Warrier, "Silica Alcogels for Possible Nuclear Waste Confinement-A Simulated Study," Materials Letters, Vol. 61, No. 11-12, 2007, pp. 2398-2401. doi:10.1016/j.matlet.2006.09.022 